\title{
Electrical Response of CdS Thin Film and CdS/Si Heterojunction to Gamma Radiation
}

\author{
M. R. Balboul, ${ }^{1}$ A. Abdel-Galil, ${ }^{1}$ I. S. Yahia, ${ }^{2}$ and A. Sharaf ${ }^{3}$ \\ ${ }^{1}$ Solid State and Accelerators Department, NCRRT, Atomic Energy Authority, P.O. Box 29, Nasr City, Cairo, Egypt \\ ${ }^{2}$ Physics Department, Faculty of Education, Ain Shams University, P.O. Box 29, Nasr City, Cairo, Egypt \\ ${ }^{3}$ Radiation Engineering Department, NCRRT, Atomic Energy Authority, P.O. Box 29, Nasr City, Cairo, Egypt
}

Correspondence should be addressed to M. R. Balboul; m_balboul@yahoo.com

Received 28 January 2016; Accepted 28 April 2016

Academic Editor: Filippo Giannazzo

Copyright (C) 2016 M. R. Balboul et al. This is an open access article distributed under the Creative Commons Attribution License, which permits unrestricted use, distribution, and reproduction in any medium, provided the original work is properly cited.

\begin{abstract}
Gamma irradiation method has been used to change the electrical properties of CdS thin film. A specific dose of $\gamma$-irradiation increases the activation energy of CdS thin film. In addition, $\gamma$-irradiation was used to change the sign of Hall coefficient, $R_{\mathrm{H}}$, of CdS thin film from negative to positive irrespective of temperature. The Hall mobility mechanism shows noticeable change after $\gamma$-irradiation from decreasing to increasing with raising the temperature. In depth, analysis was done using capacitance-voltage measurement in order to realize the modification in the CdS/Si junction band gap after $\gamma$-irradiation. Several parameters were also studied such as charge carrier concentration, $N_{\mathrm{D}}$, and flat band potential, $V_{\mathrm{fb}}$. The $\gamma$-irradiation was found to increase the concentration of the deep traps within the band gap of the CdS/Si heterojunction.
\end{abstract}

\section{Introduction}

Cadmium sulfide (CdS), with typical II-VI semiconductor properties, is a basic object of nanotechnology where the modification of their electrical and optical properties provides nanomaterials with unique application in the fields of electronics and optoelectronic devices [1-3]. The electrical properties of II-VI semiconductor compounds are drastically affected by impurities and native defects, which can be controlled by several techniques such as gamma irradiation [4-7].

The irradiation creates a wide variety of defect states in the material system by ionization or excitation processes which form new electronic configuration coordinates that cause a change in electrical response of the material and consequently its physical properties $[8,9]$. These changes are strongly dependent on the exposure dose.

Several methods are reported for the preparation of CdS using relatively simple, inexpensive, and scalable technique [10-12]. Hydrothermal method is one of the newest chemical methods which achieved these requirements to produce CdS in large area of industrial applications [13]. Thin films active devices now occupy a prominent place in research and solid-state technology. The optimization of CdS films characteristics has created a need for a better understanding of its electrical properties, which have been investigated intensively, while few studies on gamma irradiation have been available in the literature $[8,14,15]$. The novelty of this study is to modify the electrical properties of CdS thin films by exposing them to specific doses of gamma irradiation, which makes change in dc electrical conductivity, carrier concentration, Hall mobility, Hall coefficient, and flat band potential.

\section{Experimental}

Thin films of CdS have been prepared by electron beam evaporation method using vacuum coating unit (Edwards modal number E306) at a pressure of about $5.3 \times 10^{-3} \mathrm{~Pa}$ on wellcleaned glass substrate (soda-lime glass) and Si wafer (p-type) in order to form CdS/Si heterojunction. The starting nanostructured CdS powder was prepared by hydrothermal process, which has been explained elsewhere [16]. All chemicals used in the present work were of analytical grade without any further purification. The chemical composition and structure 


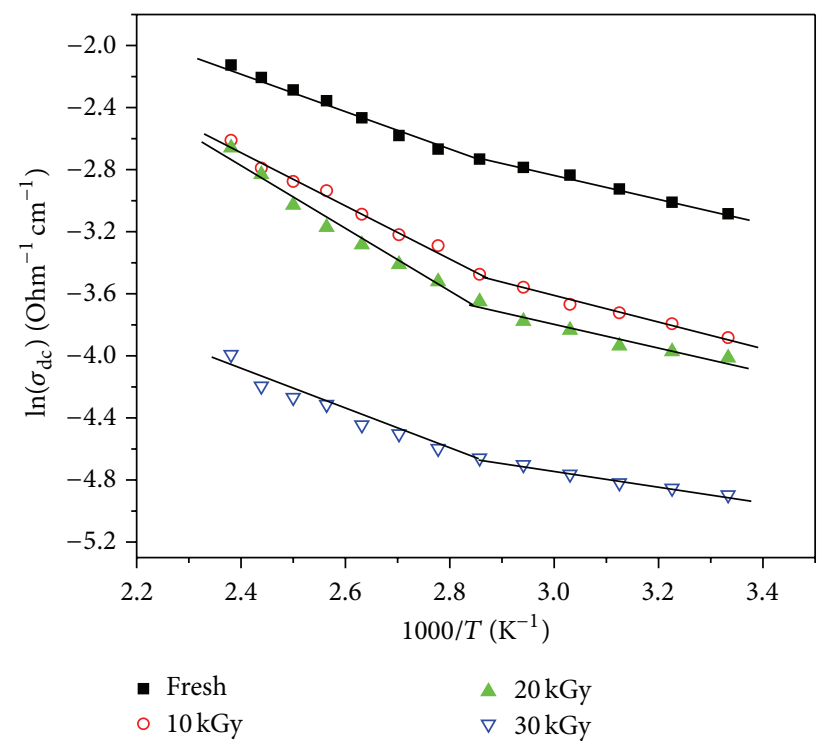

FIgURE 1: Temperature dependence of the dc conductivity, $\sigma_{\mathrm{dc}}$, for the investigated CdS thin film before and after $\gamma$-irradiation with different doses.

phase of the powder and as-deposited thin film samples were investigated using EDX and XRD techniques, respectively. The analysis confirmed the homogeneity and nanostructural nature of the CdS thin films as explained elsewhere [16].

A Cobalt-60 Indian Gamma cell GC4000A was used for irradiating the thin film samples at 10,20, and $30 \mathrm{kGy}$ (accumulative doses) and electrical measurements were analyzed before and after irradiation. For the dc conductivity and Hall Effect measurements the prepared films have a rectangular shape and four electrodes were made by silver paste on the four sides. A Keithly-617 electrometer and Oxford cryostat (DN1710) connected to automatic temperature controller were used for measuring the resistance of the thin film samples under vacuum and within temperature range of $300-$ $420 \mathrm{~K}$. Hall coefficient was measured in the same temperature range and under the effect of magnetic field up to $3.2 \mathrm{kG}$. The capacitance-voltage $(C-V)$ measurements of $\mathrm{CdS} / \mathrm{Si}$ heterojunction were obtained at constant frequency of $10^{6} \mathrm{~Hz}$ using a computer controlled LRC bridge model HIOKI 3535 in the same temperature range from 300 to $420 \mathrm{~K}$.

\section{Results and Discussion}

3.1. dc Electrical Conductivity. The variation of dc electrical conductivity $\left(\sigma_{\mathrm{dc}}\right)$ as a function of temperature $(300-420 \mathrm{~K})$ for CdS thin film was recorded prior to and after $\gamma$-irradiation ranging from 10 to $30 \mathrm{kGy}$ and shown in Figure 1. The graph showed an increase in the dc conductivity over the entire temperature range but in two different conduction mechanisms. This means that the conduction in this film is through an activated process having dual transport mechanisms at high and relatively lower temperatures range. At high temperature range from about 350 to $420 \mathrm{~K}$, the conduction is due to the
TABLE 1: The value of radiation dose, dc conductivity $\left(\sigma_{\mathrm{dc}}\right)$, and activation energy $\left(\Delta E_{1}\right.$ and $\left.\Delta E_{2}\right)$.

\begin{tabular}{lccc}
\hline Dose & $\begin{array}{c}\sigma_{\mathrm{dc}}(\text { at } 340 \mathrm{~K}) \\
\left(\mathrm{Ohm}^{-1} \mathrm{~cm}^{-1}\right)\end{array}$ & $\begin{array}{l}\Delta E_{1} \\
(\mathrm{eV})\end{array}$ & $\begin{array}{l}\Delta E_{2} \\
(\mathrm{eV})\end{array}$ \\
\hline Fresh & $6.17 \times 10^{-2}$ & 0.262 & 0.151 \\
$10 \mathrm{kGy}$ & $2.85 \times 10^{-2}$ & 0.338 & 0.166 \\
$20 \mathrm{kGy}$ & $2.29 \times 10^{-2}$ & 0.427 & 0.172 \\
$30 \mathrm{kGy}$ & $9.08 \times 10^{-3}$ & 0.260 & 0.101 \\
\hline
\end{tabular}

thermally activated conduction of electron in the potential barrier and the next relation can express $\sigma_{\mathrm{dc}}$ :

$$
\sigma_{\mathrm{dc}}=\sigma_{o} \exp \left(\frac{-\Delta E_{1}}{k_{\mathrm{B}} T}\right),
$$

where $\sigma_{o}$ is the preexponential factor, $\Delta E_{1}$ is the dc activation energy, and $k_{\mathrm{B}}$ is the Boltzmann constant, while at relativity low temperature from about 300 to $350 \mathrm{~K}$ the conduction is due to transition of charge carriers between the localized states by hopping near the Fermi level [17] and $\sigma_{\mathrm{dc}}$ can be given by the following relation:

$$
\sigma_{\mathrm{dc}}=\sigma_{1} \exp \left(\frac{-\Delta E_{2}}{k_{\mathrm{B}} T}\right),
$$

where $\sigma_{1}$ is the preexponential factor and $\Delta E_{2}$ is the activation energy. Table 1 shows the values of $\sigma_{\mathrm{dc}}$ at $340 \mathrm{~K}, \Delta E_{1}$, and $\Delta E_{2}$. The activation energy was calculated from the slope of the curve shown in Figure 1. From this table we can observe that $\sigma_{\mathrm{dc}}$ decreases with increasing $\gamma$-irradiation doses. On the other hand, $\Delta E_{1}$ and $\Delta E_{2}$ increase firstly with doses up to $20 \mathrm{KGy}$ and then decrease at $\gamma$ dose of $30 \mathrm{KGy}$. This increment in both $\Delta E_{1}$ and $\Delta E_{2}$ with $\gamma$-irradiation up to $20 \mathrm{KGy}$ can be attributed to the increase in defect states within the band gap especially at the edges of the extended states and near the Fermi level, respectively [17]. Further increase in the $\gamma$-dose (30 KGy) can cause rearrangement in the chemical bonds in the system $[18,19]$. Therefore, the energy splitting between the states of the valence and conduction bands will change and in consequence both $\Delta E_{1}$ and $\Delta E_{2}$ are changed.

3.2. Hall Coefficient. The temperature dependence of the Hall coefficient, $R_{\mathrm{H}}$, for fresh and irradiated CdS thin films is displayed in Figure 2. The experimental $R_{\mathrm{H}}$ values were calculated in temperature range from 300 to $420 \mathrm{~K}$ and under constant applied magnetic field of $B=3.2 \mathrm{kG}$ using the following relation:

$$
R_{\mathrm{H}}=\frac{V_{\mathrm{H}} d}{I B},
$$

where $V_{\mathrm{H}}$ is the transverse voltage difference, $d$ is the thickness of the film, $I$ is the longitudinal current, and $B$ is the perpendicular applied magnetic field. It is found that the Hall coefficient of fresh CdS sample is negative irrespective of temperature, which indicates that the fresh sample is $n$-type semiconductor material and the electrons are the majority carriers while holes are the minority carriers as illustrated in 


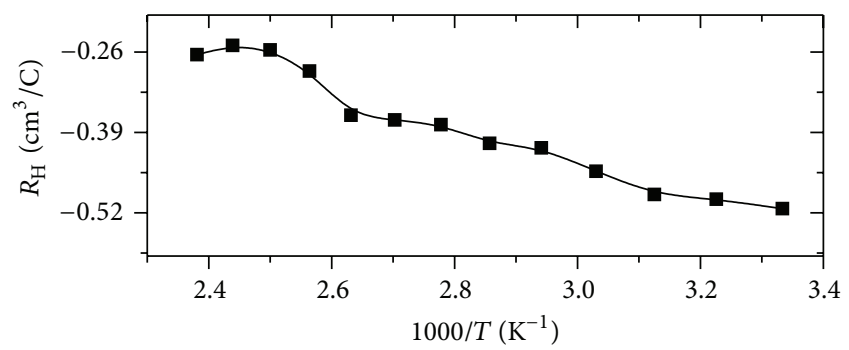

- - Fresh

(a)

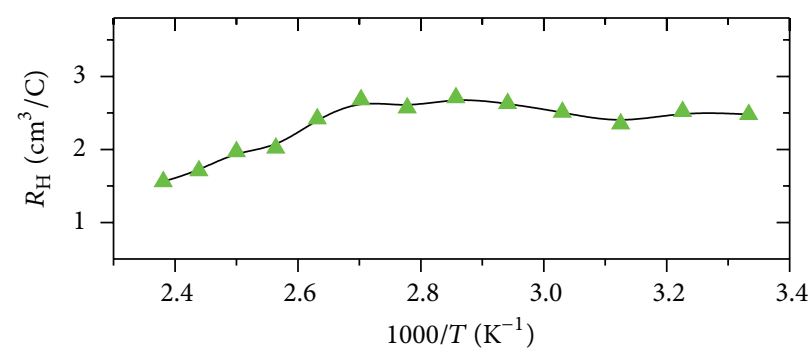

$-\Delta-20 \mathrm{kGy}$

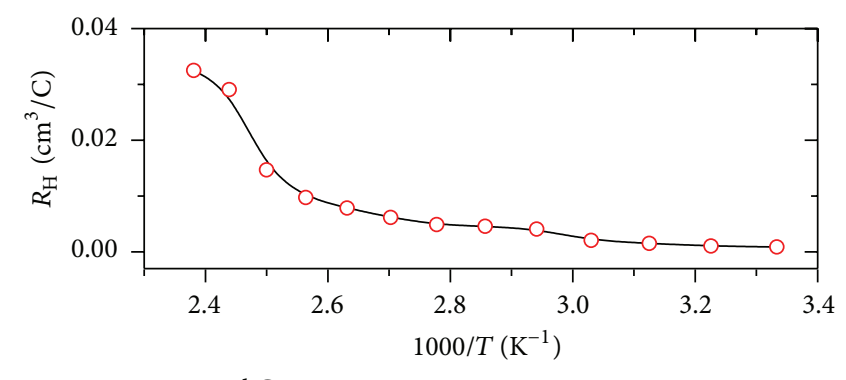

- - $10 \mathrm{kGy}$

(b)

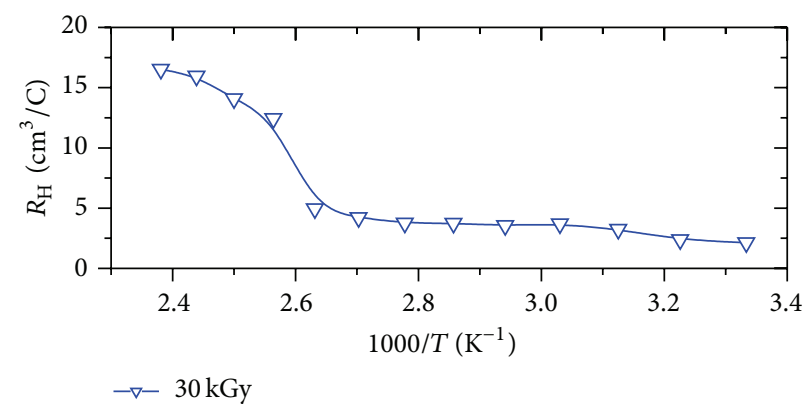

(d)

Figure 2: Temperature dependence of Hall coefficient, $R_{\mathrm{H}}$, for the investigated CdS thin film (a) before and (b-d) after $\gamma$-irradiation with different doses.

Figure 2(a). With irradiation, the sign of $R_{\mathrm{H}}$ is changed from negative to positive irrespective of temperature as shown in Figures 2(b)-2(d). This means that the $\gamma$-irradiation changes the carrier concentration in the CdS sample. In other words, the defects which are generated and the rearrangement in the chemical bonds in the CdS system caused by $\gamma$-irradiation change the number of the free charge carriers, electrons, and holes, in the sample and consequently the semiconductor type of CdS film, from n-type to p-type. This has been clarified after calculating the charge carriers number $N$ and Hall mobility coefficients $\mu_{\mathrm{H}}$. First, $N$ was calculated using the following relation [20]:

$$
N=\frac{1}{e R_{\mathrm{H}}}
$$

where $e$ is the electron charge and $R_{\mathrm{H}}$ is the Hall coefficient. Figure 3 shows the charge carriers concentration of the fresh and irradiated CdS film in the temperature range from 300 to $420 \mathrm{~K}$. From the data shown in Figure 3 it can be inferred that the charge carriers have different behavior with temperature and different transport mechanisms [21, 22]. Moreover, this behavior changed completely after specific dose of $\gamma$-irradiation as shown in Figure 3(c), where the slope changed from negative to positive.

Second, the Hall mobility $\mu_{\mathrm{H}}$ was calculated using the well-known relation [23]:

$$
\mu_{\mathrm{H}}=\sigma_{\mathrm{dc}} R_{\mathrm{H}},
$$

where $\sigma_{\mathrm{dc}}$ is the dc conductivity. Figure 4 shows the temperature dependence of Hall mobility for the fresh and irradiated
CdS thin film in the temperature range from 300 to $420 \mathrm{~K}$. This figure illustrates the clear changes in the Hall mobility mechanism with temperature after $\gamma$-irradiation from decreasing to increasing with raising the temperature. For the fresh CdS sample (Figure 4(a)), with increasing temperature, the carriers are scattered by an increasing number of thermally generated acoustic phonons and the mobility decreases with temperature, while for irradiated samples (Figures 4(b)$4(d))$, the increase of the mobility with temperatures can be explained by an increase in the thermal velocity of the free carriers. In addition, the defects created by $\gamma$-radiation, which act as dopants and ionized scattering centers [24], will cause a smaller deflection in the carriers (Rutherford Scattering). Furthermore, it can be noted that the mobility of the charge carriers increases with the increase of $\gamma$-doses.

3.3. $C-V$ Measurements. Figure 5 shows Mott-Schottky plots $\left(1 / C^{2}\right.$ versus $\left.V\right)$ of fresh and irradiated CdS thin film (Schottky contact) deposited on p-type Si wafer surface. The ambient temperature was varied from 300 to $420 \mathrm{~K}$ at constant frequency of $10^{6} \mathrm{~Hz}$. This plot illustrates a strong dependence of the behavior of $1 / C^{2}$ on heating temperature. In the temperature range from 310 up to $420 \mathrm{~K}$ the plot shows almost a linear relationship with a positive slope according to an n-type semiconductor, while at room temperature, $300 \mathrm{~K}$, there are three main features which protrude (marked by (1), (2), and (3) in Figure 5(a)). In the first feature, the slope of the curves changes positively with the applied bias voltages up to $\approx 2 \mathrm{~V}$, while in the second feature, the capacitance remains nearly constant with the applied bias voltages in the range from about 2 up to $3.5 \mathrm{~V}$ for the fresh sample (marked by 


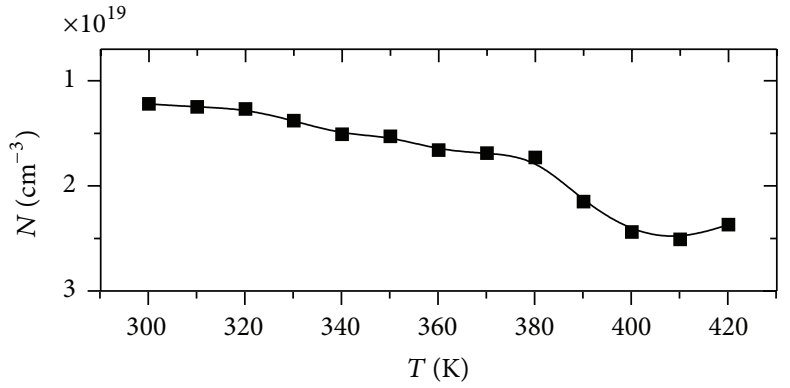

-- Fresh

(a)

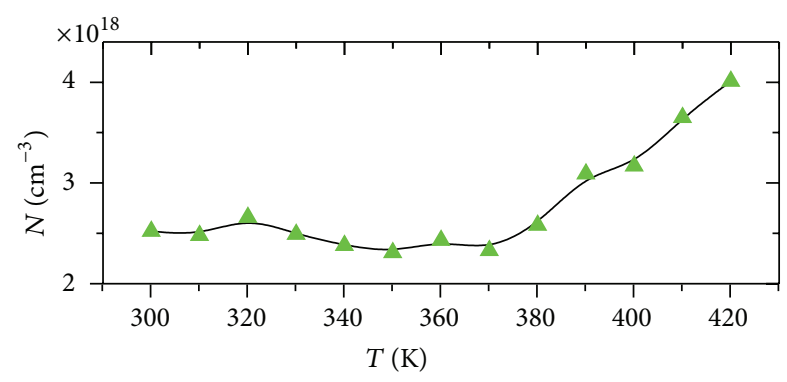

$-\sim 20 \mathrm{kGy}$

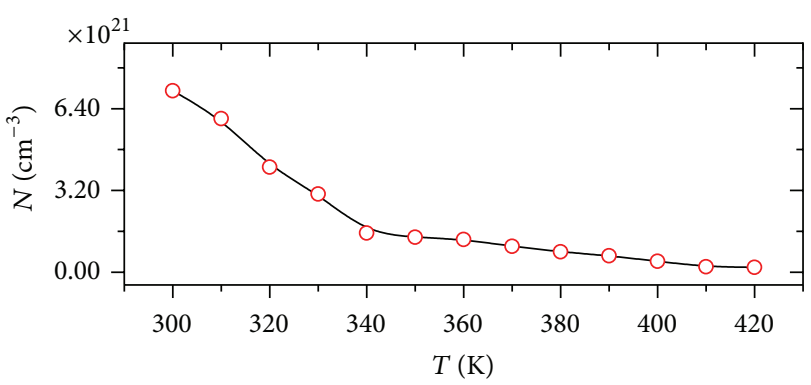

(b)

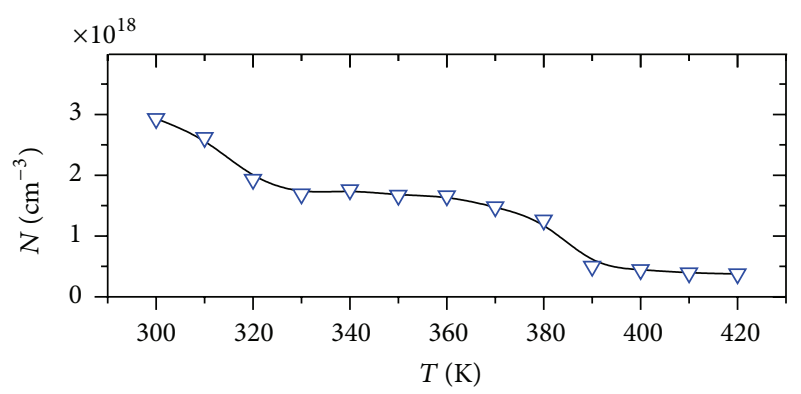

$-\nabla-30 \mathrm{kGy}$

(c)

(d)

FIGURE 3: Temperature dependence of carrier concentration, $N$, for the investigated CdS thin film (a) before and (b-d) after $\gamma$-irradiation with different doses.

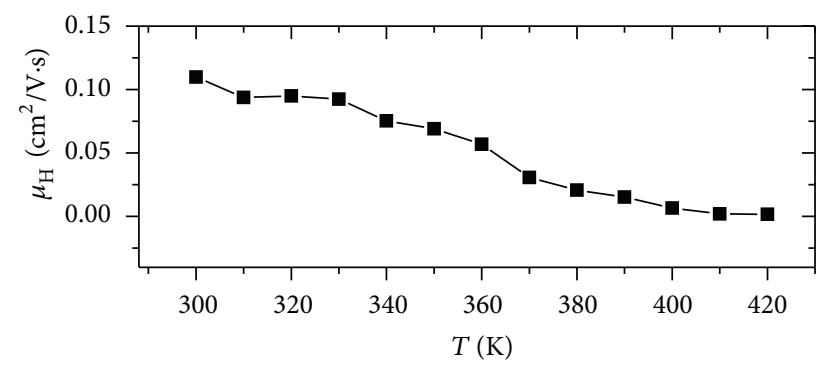

(a)

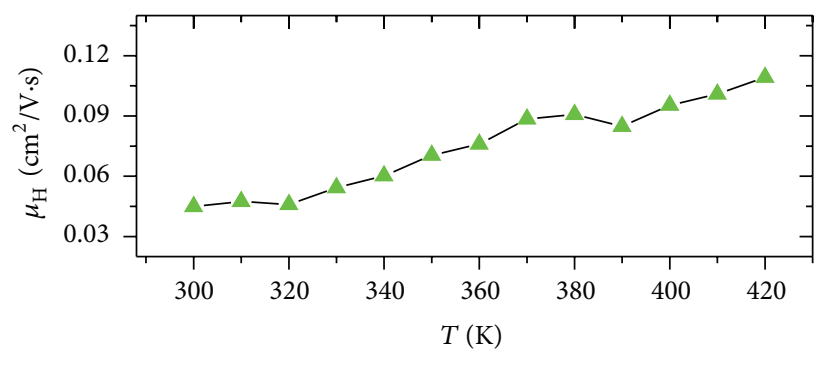

$-\sim 20 \mathrm{kGy}$

(c)

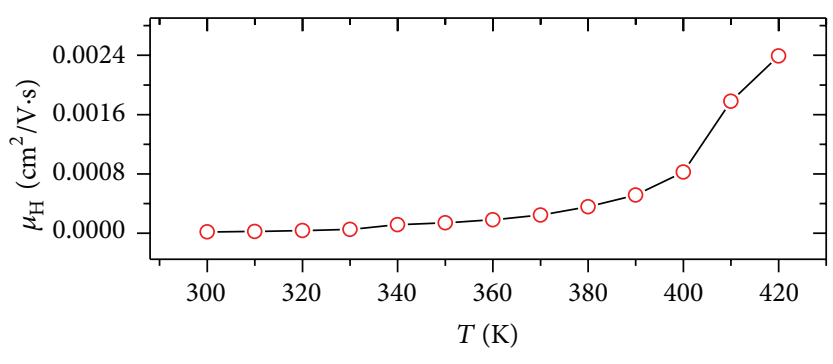

(b)

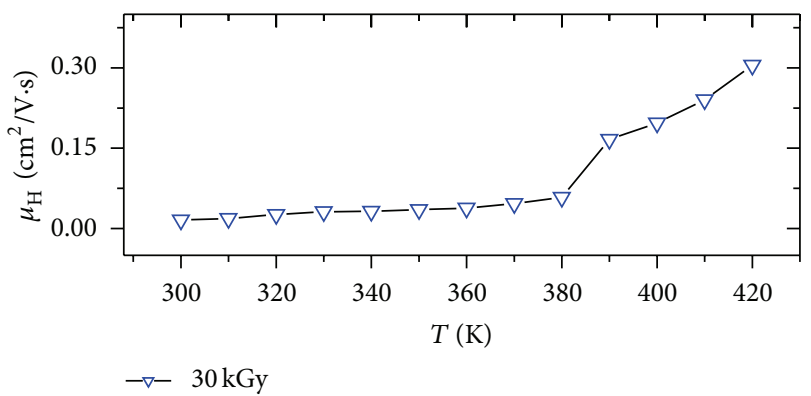

(d)

FIGURE 4: Temperature dependence of Hall mobility, $\mu_{\mathrm{H}}$, for the investigated CdS thin film (a) before and (b-d) after $\gamma$-irradiation with different doses. 


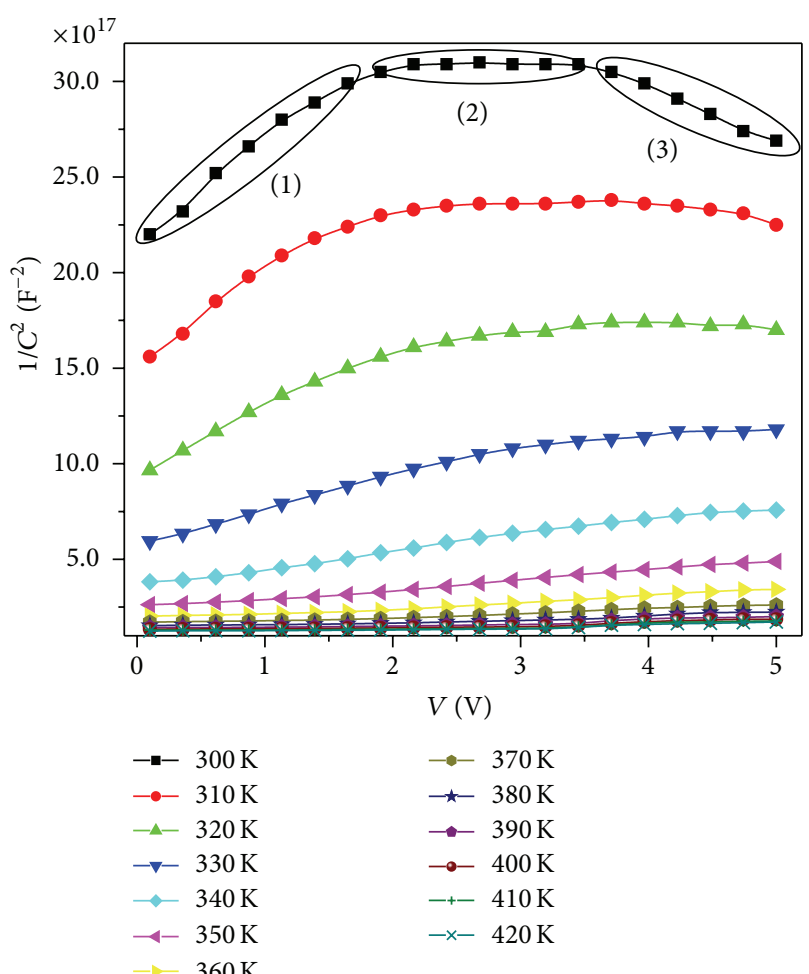

(a) Fresh

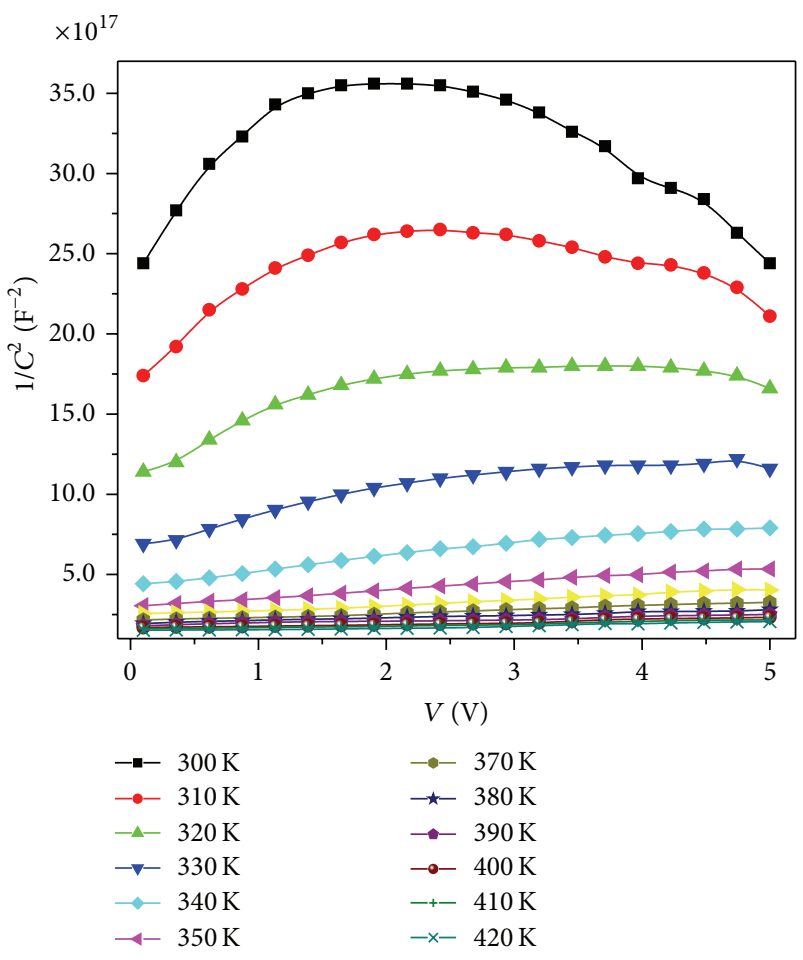

(c) $20 \mathrm{kGy}$

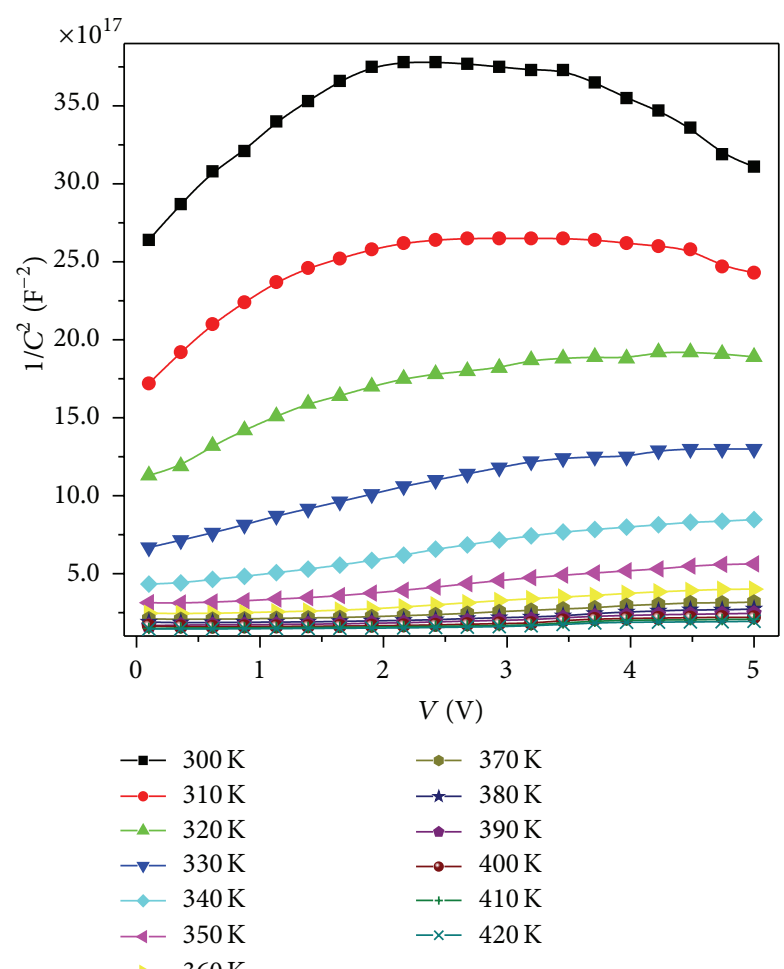

(b) $10 \mathrm{kGy}$

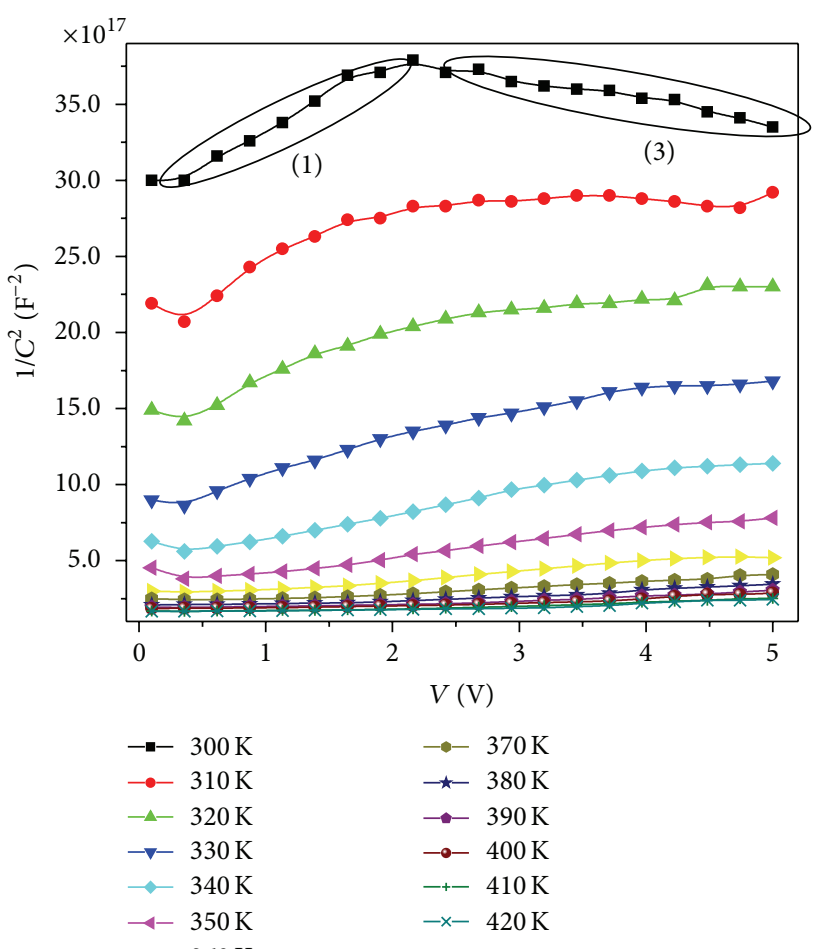

(d) $30 \mathrm{kGy}$

FIGURE 5: Temperature dependence of Mott-Schottky plot for the investigated CdS/Si heterojunction at different temperature (a) before and (b-d) after $\gamma$-irradiation with different doses. 
(2) in Figure 5(a)) and this range decreases with increasing irradiation dose until it vanished at $30 \mathrm{kGy}$ (Figure 5(d)). In the third feature, the slope of the curves changes to negative sign with the applied bias voltages from 3.5 up to $5 \mathrm{~V}$ and this range increases with increase in the irradiation dose (marked by (3) in Figure 5(d)).

The change in the capacitance behavior with the applied bias voltages and irradiation doses, at room temperature, can be explained by the influence of the high concentration of deep traps within the band gap of the CdS semiconductor material [25]. Depending on their occupational status, they contribute or do not contribute to the measured capacitance [26]. A change in bias voltage and/or irradiation dose causes a shift of the Fermi energy level. Consequently, the occupation state of the deep traps within an energy range close to the Fermi level changes which results in a variation in the net doping concentration and, therefore, a change in the slope of the $C-V$ characteristics [27], while raising the temperature above the room temperature limits the impact of these deep traps within the band gap and the slope behavior of the capacitance becomes almost constant with applied bias voltages.

The charge carrier concentration and flat band potential are defined by Mott-Schottky relationship in the linear part of $1 / C^{2}$ versus $V$ plot:

$$
\frac{1}{C^{2}}=\frac{2}{N_{\mathrm{D}} e \varepsilon \varepsilon_{0} A^{2}}\left[\left(V-V_{\mathrm{fb}}\right)-\frac{k T}{e}\right],
$$

where $N_{\mathrm{D}}$ is the charge carrier concentration, $e$ is the electron charge, $\varepsilon$ is the dielectric constant, $\varepsilon_{0}$ is the permittivity of free space, $A$ is the electrode surface area, and $V_{\mathrm{fb}}$ is the flat band potential, which is the applied potential at which the semiconductor energy bands are flat. Therefore, $V_{\mathrm{fb}}$ can be determined from the intercept on $V$ axis and the value of $N_{\mathrm{D}}$ from the slope by knowing $\varepsilon$ and $A$.

Figures 6 and 7 show the variation of charge carrier concentration and the flat band potential, respectively, with temperature for fresh and irradiated Schottky contact sample. As shown in these figures it can be observed that both the charge carrier concentration and negativity of the flat potential increase with the temperature and decrease with $\gamma$ irradiation doses. It is well known that the flat band potential is the potential (or voltage) at which the band bending disappears and the thickness of the space charge layer is (theoretically) zero and the capacity becomes infinitely large. In our case, we have found that both the charge carrier concentration and negativity of the flat potential increase with the temperature and decrease with $\gamma$-irradiation. This means that the $\gamma$-irradiation works against temperature; that is, space charge layer thickness decreases with irradiation doses and hence the flat potential.

\section{Conclusion}

The obtained results confirmed that $\gamma$-irradiation could be used to modify the dc electrical conductivity and activation energy of CdS thin film. Doses of 10 and $20 \mathrm{KGy}$ increase both $\Delta E_{1}$ and $\Delta E_{2}$, while $\sigma_{\mathrm{dc}}$ decreases with doses up to $30 \mathrm{KGy}$. Measuring $R_{\mathrm{H}}$ values of CdS thin film sample confirmed

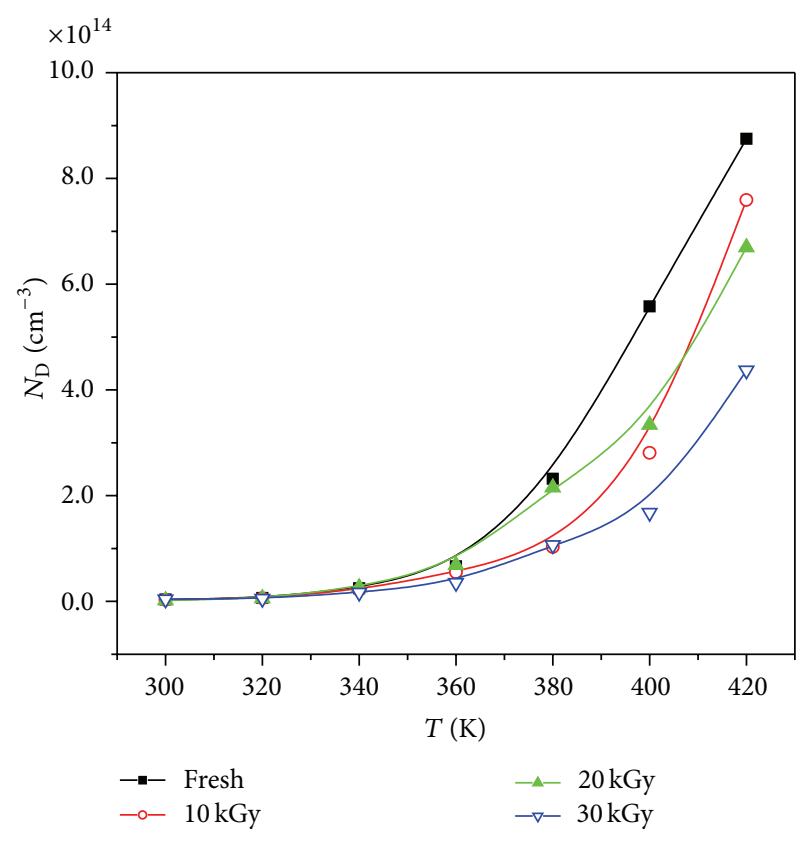

FIGURE 6: Temperature dependence of charge carrier concentration for the investigated $\mathrm{CdS} / \mathrm{Si}$ heterojunction before and after $\gamma$ irradiation with different doses.

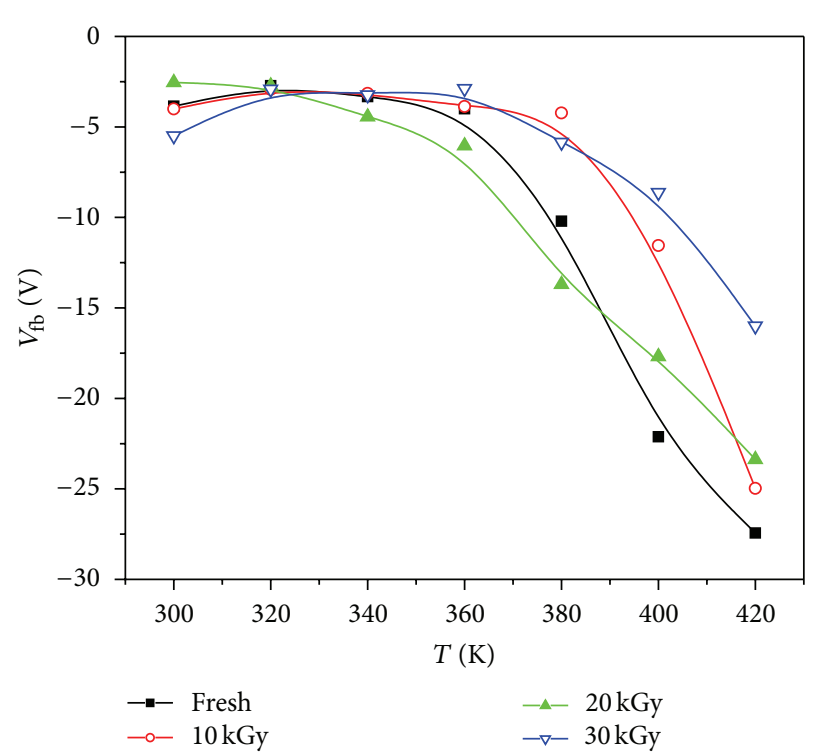

FIGURE 7: Temperature dependence of flat potential for the investigated $\mathrm{CdS} / \mathrm{Si}$ heterojunction before and after $\gamma$-irradiation with different doses.

the possibility to change the number of free charge carriers (electrons and holes) in the sample and consequently the type from n-type to p-type. Moreover, $\gamma$-irradiation changes the Hall mobility mechanism with raising the temperature from decreasing before irradiation to increasing after irradiation. In addition, based on the results obtained from measuring $C-V$ of CdS/Si Schottky contact, the $\gamma$-irradiation strongly affects the net doping concentration within the band gap of 
the CdS/Si heterojunction. The charge carrier concentration and flat band potential were affected also by $\gamma$-irradiation.

\section{Competing Interests}

The authors declare that they have no competing interests.

\section{References}

[1] A. S. Z. Lahewil, Y. Al-Douri, U. Hashim, and N. M. Ahmed, "Structural and optical investigations of cadmium sulfide nanostructures for optoelectronic applications," Solar Energy, vol. 86, no. 11, pp. 3234-3240, 2012.

[2] A. Rios-Flores, O. Arés, J. M. Camacho, V. Rejon, and J. L. Peña, "Procedure to obtain higher than $14 \%$ efficient thin film $\mathrm{CdS} / \mathrm{CdTe}$ solar cells activated with $\mathrm{HCF}_{2} \mathrm{Cl}$ gas," Solar Energy, vol. 86, no. 2, pp. 780-785, 2012.

[3] A. Schüler, M. Python, M. V. del Olmo, and E. de Chambrier, "Quantum dot containing nanocomposite thin films for photoluminescent solar concentrators," Solar Energy, vol. 81, no. 9, pp. 1159-1165, 2007.

[4] S. Del Sordo, L. Abbene, E. Caroli, A. M. Mancini, A. Zappettini, and P. Ubertini, "Progress in the development of CdTe and $\mathrm{CdZnTe}$ semiconductor radiation detectors for astrophysical and medical applications," Sensors, vol. 9, no. 5, pp. 3491-3526, 2009.

[5] M. Ashry and S. A. Fayek, "Radiation effects on fabricated $\mathrm{Cu}_{2} \mathrm{~S} / \mathrm{CdS}$ heterojunction photovoltaic cells," Renewable Energy, vol. 23, no. 3-4, pp. 441-450, 2001.

[6] S. Kasap and P. Capper, Eds., Springer Handbook of Electronic and Photonic Materials, Springer, 2006.

[7] M. R. Balboul, H. M. Hosni, and S. A. Fayek, "Effect of $\mathrm{Co}^{60} \gamma$ irradiation on the optical properties of thin films from the system $\mathrm{GeSe}_{3}-\mathrm{Sb}_{2} \mathrm{Se}_{3}-\mathrm{ZnSe}$," Radiation Physics and Chemistry, vol. 81, no. 12, pp. 1848-1855, 2012.

[8] A. M. Saad, A. K. Fedotov, A. V. Mazanik et al., "Modification of electrical properties of $\mathrm{CdS}_{x} \mathrm{Se}_{1-x}$ films by hard irradiation and nanostructuring," Thin Solid Films, vol. 487, no. 1-2, pp. 202-204, 2005.

[9] M. Husham, Z. Hassan, M. A. Mahdi, A. M. Selman, and N. M. Ahmed, "Effect of gamma-ray irradiation on the size and properties of CdS quantum dots in reverse micelles," Radiation Physics and Chemistry, vol. 92, pp. 87-92, 2013.

[10] M. A. Barote, A. A. Yadav, and E. U. Masumdar, "Synthesis, characterization and photoelectrochemical properties of n-CdS thin films," Physica B: Condensed Matter, vol. 406, no. 10, pp. 1865-1871, 2011.

[11] S. Patra, P. Mitra, and S. K. Pradhan, "Preparation of nanodimensional CdS by chemical dipping technique and their characterization," Materials Research, vol. 14, no. 1, pp. 17-20, 2011.

[12] S. Mathew, P. S. Mukerjee, and K. P. Vijayakumar, "Optical and surface properties of spray-pyrolysed CdS thin films," Thin Solid Films, vol. 254, no. 1-2, pp. 278-284, 1995.

[13] Y. C. Goswami, R. Sharma, and P. Rajaram, "Growth of CdS nanostrutcures by new sol gel route and its optical characterization," Nanotechnology and Nanoscience, vol. 2, pp. 38-41, 2011.

[14] O. Goncharova, V. Kalinov, and A. Voitovich, "The energy transfer in irradiated dielectric thin film structures with CdS and CdSe nanocrystals," Radiation Measurements, vol. 38, no. 4-6, pp. 775-779, 2004.
[15] M. E. Moussa, M. Y. Feteha, and M. F. M. Hassan, "Gamma irradiated CdS(In)/p-Si heterojunction solar cell," Renewable Energy, vol. 23, no. 3-4, pp. 361-367, 2001.

[16] A. Abdel-Galil, M. R. Balboul, A. Atta, I. S. Yahia, and A. Sharaf, "Preparation, structural and optical characterization of nanocrystalline CdS thin film," Physica B: Condensed Matter, vol. 447, pp. 35-41, 2014.

[17] N. F. Mott and E. A. Davis, Electronic Process in Non-Crystalline Materials, Clarendon Press, Oxford, UK, 1979.

[18] V. O. Balitska and O. I. Shpotyuk, "Radiation-induced structural transformations in vitreous chalcogenide semiconductors," Journal of Non-Crystalline Solids, vol. 227-230, no. 2, pp. 723727,1998

[19] M. R. Balboul, "Optical effects induced by gamma and UV irradiation in chalcogenic glass," Radiation Measurements, vol. 43, no. 8, pp. 1360-1364, 2008.

[20] Y. Natsume and H. Sakata, "Electrical and optical properties of zinc oxide films post-annealed in $\mathrm{H}_{2}$ after fabrication by solgel process," Materials Chemistry and Physics, vol. 78, no. 1, pp. 170-176, 2003.

[21] T. M. W. J. Bandara, M. A. K. L. Dissanayake, I. Albinsson, and B. E. Mellander, "Mobile charge carrier concentration and mobility of a polymer electrolyte containing PEO and $\operatorname{Pr}_{4} \mathrm{~N}^{+} \mathrm{I}^{-}$ using electrical and dielectric measurements," Solid State Ionics, vol. 189, no. 1, pp. 63-68, 2011.

[22] O. D. Bekasova, A. A. Revina, A. L. Rusanov, E. S. Kornienko, and B. I. Kurganov, "Effect of gamma-ray irradiation on the size and properties of CdS quantum dots in reverse micelles," Radiation Physics and Chemistry, vol. 92, pp. 87-92, 2013.

[23] M. H. Cohen, H. Fritzsche, and S. R. Ovshinsky, "Simple band model for amorphous semiconducting alloys," Physical Review Letters, vol. 22, no. 20, pp. 1065-1068, 1969.

[24] A. Mekys, J. Storasta, A. Zindulis, A. P. Smilga, and S. Balakauskas, "Hall mobility field effect in two layer conductivity samples," Acta Physica Polonica A, vol. 114, no. 4, pp. 903-912, 2008.

[25] M. Turcu, I. M. Kötschau, and U. Rau, "Composition dependence of defect energies and band alignments in the $\mathrm{Cu}\left(\mathrm{In}_{1-x} \mathrm{Ga}_{x}\right)\left(\mathrm{Se}_{1-y} \mathrm{~S}_{y}\right)_{2}$ alloy system," Journal of Applied Physics, vol. 91, no. 3, pp. 1391-1399, 2002.

[26] E. Schlenker, V. Mertens, J. Parisi, R. Reineke-Koch, and M. Köntges, "Schottky contact analysis of photovoltaic chalcopyrite thin film absorbers," Physics Letters, Section A: General, Atomic and Solid State Physics, vol. 362, no. 2-3, pp. 229-233, 2007.

[27] L. C. Kimerling, "Influence of deep traps on the measurement of free-carrier distributions in semiconductors by junction capacitance techniques," Journal of Applied Physics, vol. 45, no. 4, pp. 1839-1845, 1974. 

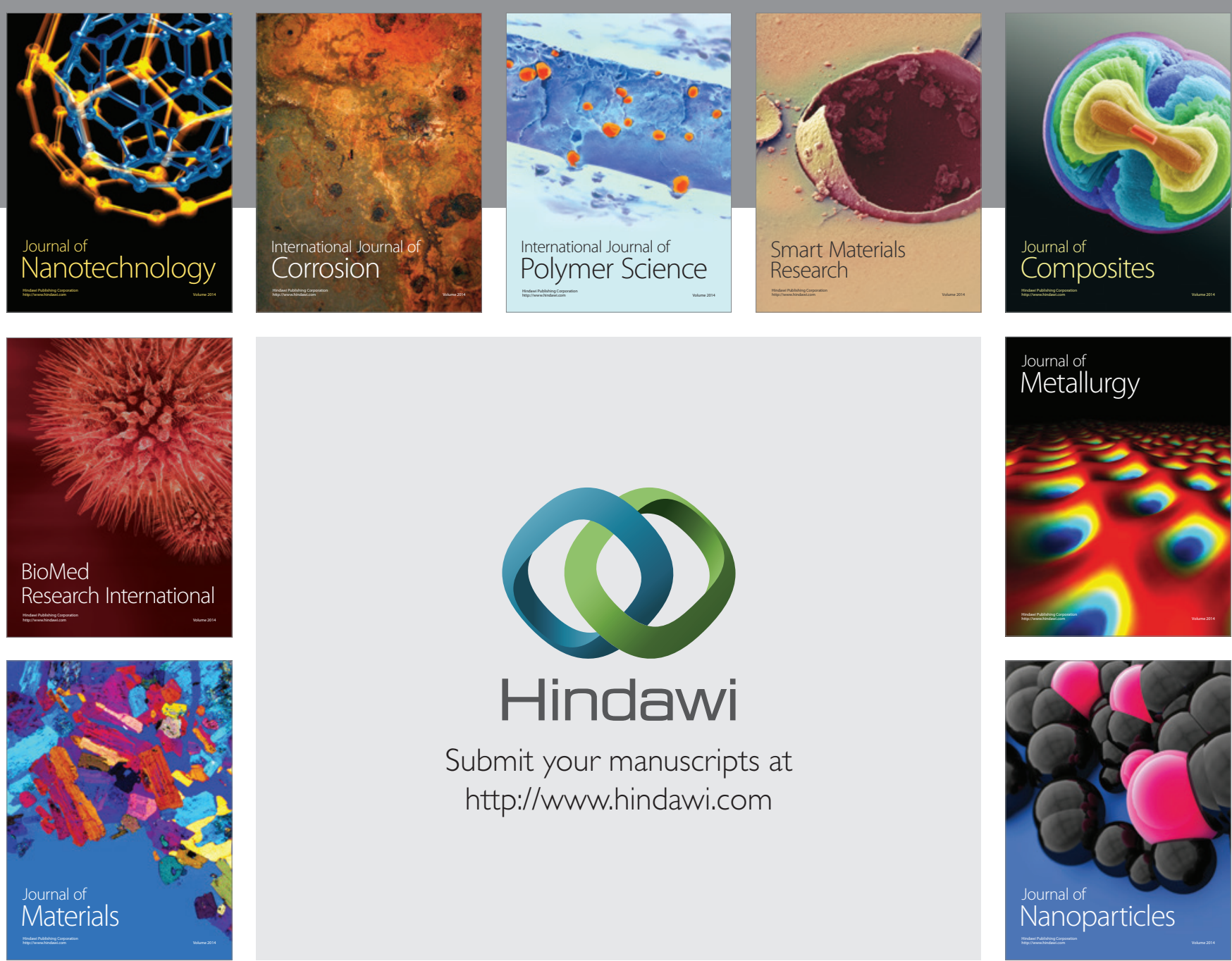

\section{Hindawi}

Submit your manuscripts at

http://www.hindawi.com

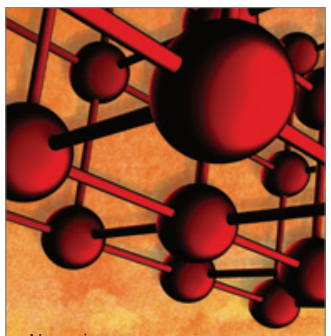

Materials Science and Engineering
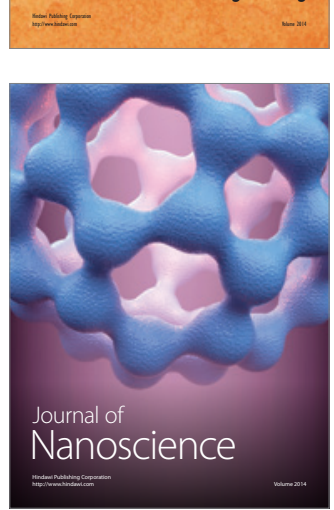
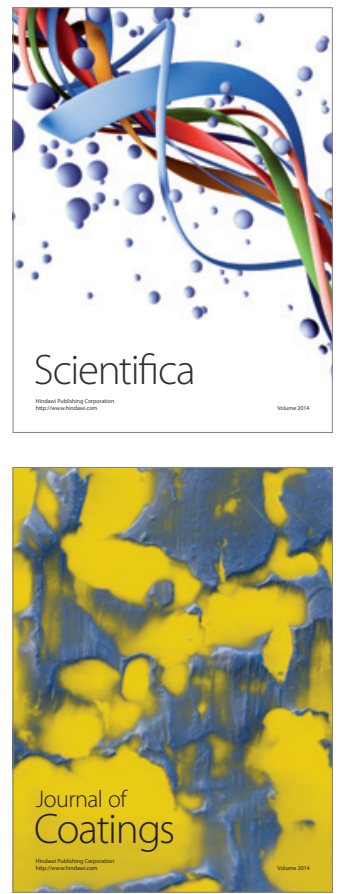
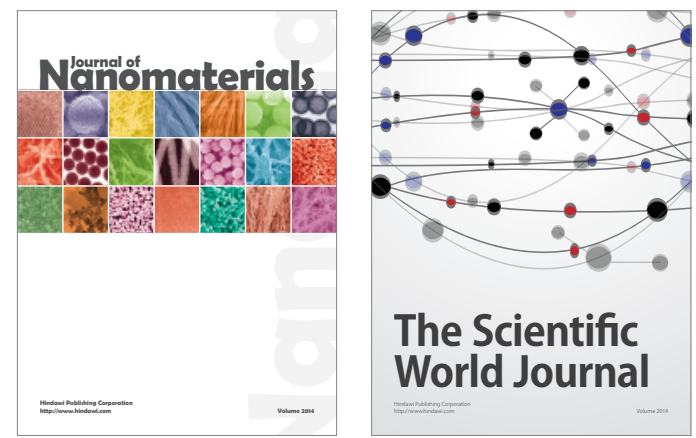

The Scientific World Journal
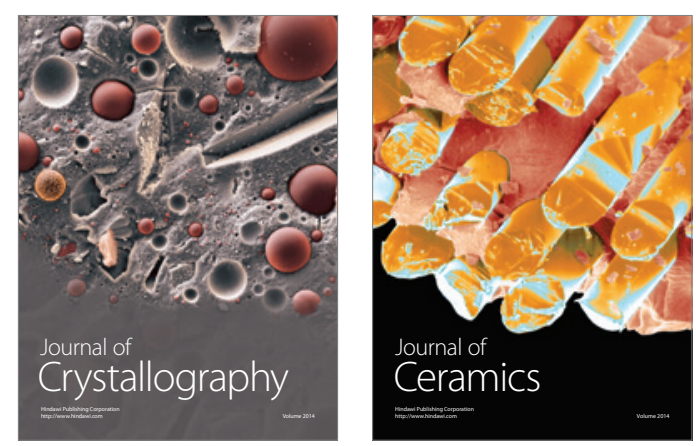
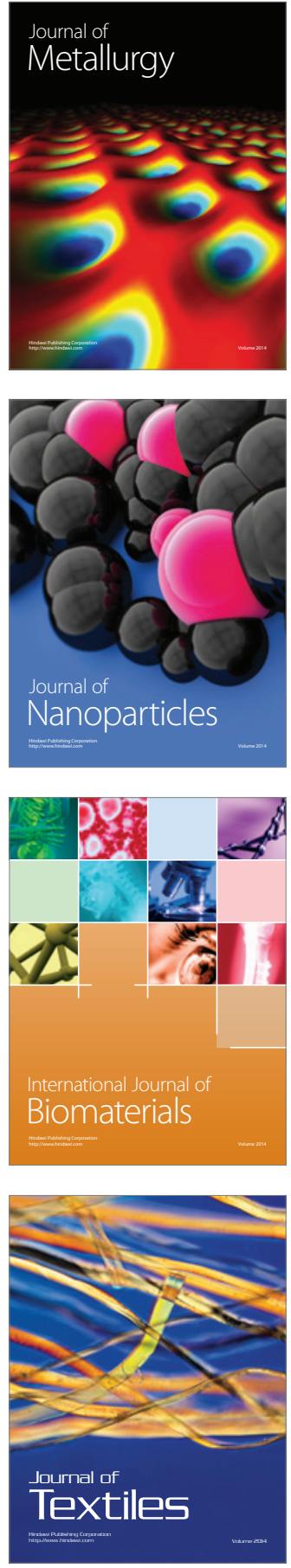